\title{
„DIE MENS NA DIE BEELD VAN GOD” IN DIE OU TESTAMENT
}

Aan die einde van die huidige akademiese jaar breek die oomblik aan dat Prof. H. P. Wolmarans sy werksaamhede in offisiële hoedanigheid aan die Universiteit van Pretoria sal beëindig. Waar hierdie nommer van die Hervormde Teologiese Studies aan hom opgedra word na 'n dienstyd van 37 jaar in die Kerk, waarvan 24 jaar aan die akademie, is dit gepas om oor die onderwerp, wat reeds voor die dae van sy promosie sy belangstelling geniet het, nou by sy uittrede as hoogleraar nog 'n keer te besin, temeer nog omdat hierdie grondstelling op die eerste bladsye van die Bybel so sterk meespreek by sy teologiese denke en beskouinge.

Dat die onderwerp nog gedurig in die middelpunt van die belangstelling van eksegetisie, dogmatisie en sistematisie staan blyk uit die publikasies wat daar van tyd tot tyd nog daaroor verskyn, ditsy regstreeks oor die onderwerp of betrek by die behandeling van aanverwante teologiese probleme. Hierdie "Grundstelle der Imago-Dei Lehre" ${ }^{\text {vind ons }}$ vir die eerste keer in Gen. 1:26 v., wat dan ook die uitgangspunt is van elke ondersoek wat gaan oor die vraag van die mens na die beeld van God. Ook in die vervolg van die boek Genesis en wel in Hk. 5 en 9 word hierop teruggekom, 'n neerslag daarvan vind ons in Psalm 8 en ook in Esegiël 28:12 v. word melding gemaak van ,die dag toe jy geskape is". Deurslaggewend is egter wat daar in Gen. 1:26 v. opgeteken staan.

Wie die verhaal van die priesterskrywer in Gen. 1:1-2:4a lees en rustig op hom laat inwerk kom onder die indruk van die verhewe eenvoud, maar ook die verwonderende aanbidding; hierdie hoofstuk is dan ook prediking in sy suiwerste en skoonste vorm. In kort sober trekke word die skepping beskrywe, hemel en aarde, die totaliteit van die geskapene. Onmiddelik na die mededeling rig die skrywer sy belangstelling na die aarde; ${ }^{2}$ die woordorde in die Hebreeuse teks wys reeds daarop. Tog gaan die skrywer gedurig uit van die gedagte dat God die een is wat skep, daar bly voortdurende wisselwerking tussen God wat skep en wat daar op die aarde besig is om te gebeur. So word die skeppingswerke dag na dag beskryf, om na die voltooiing van die dag se werk te eindig met die herhaalde - en dit was aand en dit was môre, die soveelste dag. Op die sesde dag, nadat die landdiere gemaak is, volg dan die hoogtepunt van die skeppingsdade-eie skepping van die mens. In teenstelling met die skepping van voorafgaande geskape diere, waarin ook die waters en die aarde, deur God betrek word, vs. 20 en vs. 24, vind die skepping van die mens plaas. Die mens kom direk van bo, van God af, sonder tussenKoms of toedoen van die waters of die aarde.

Toe het God gesê: Laat ons (ons wil) mense ('n mensheid) maak na ons beeld ( $b^{e}$ șalmēnû) na ons gelykenis (kidmûtēnû).

1) LUDwig KöHLER, Theologische Zeitschrift, 1948, p.16.

2) Cf. B. Gemser, Hervormde Teologiese Studies, 1946, p. 190. 
Wat dadelik opval is die eerste persoons meervoudsvorm van die werkwoord cāsâ, in die cohortatiewe of voluntatiewe vorm, wat hier die eerste keer voorkom in die skeppingswerksaamheid van God. In die loop van die eeue is hieraan verskillende verklaringe gegee. Daar was die wat hierin die nawerking gesien het van 'n politeïstiese oorblyfsel, weer ander het hierin 'n verwysing na die Driëenheid gesien, 'n pluralis majestatis, 'n beraadslaging van die Skepper met homself. Meer aanneemlik lyk dit om in die Ons 'n heenwysing te sien na die hemelse hofhouding of raad, wat nie 'n onbekende figuur in die Ou Testament is nie. cf. 1 Kon. $22: 19$ v., Jes. $6: 1$ v., Ps. 82:1, Jer. 23:18, Sag 3:1 v., Job 1:6 v., 2:1 v., 15:7, 8. Hier vind dus wel raadpleging plaas van God, maar nie met homself nie, maar met die wat rondom hom is.

In 1 Kon. 22:19 word verhaal deur Miga ben Jimla:

Ek het Jahwe sien sit op sy troon

en die hele leër van die hemel by hom staan

aan sy regter- en aan sy linkerhand.

En Jahwe het gesê: Wie sal Agab verlei, ${ }^{3}$

dat hy optrek en val by Ramot in Gilead?

en die een het sus en die andereen so gesê.

En die gees het vorentoe gekom, voor Jahwe gaan staan en gesê:

$\mathrm{Ek}$, ek sal hom verlei....

In Jes. 6:1 lees ons:

... het ek die Heere sien sit op 'n troon, hoog en verhewe, ... serafs het bo hom gestaan ... daarop hoor ek die stem van die Heere wat sê: Wie sal ek stuur en wie sal vir ons gaan en ek het gesê: Hier is ek, stuur my.

In beide gevalle vind in die besondere situasie 'n raadpleging plaas. Jahwe sit op sy troon en sy hemelse hofhouding, in die eerste geval genoem die leër van die hemel, en in Jes. 6 bevind die serafs hulle hieronder, staan by hom. Aan die wat rondom hom staan stel Hy dan die vraag-wie sal Agab verlei en in die ander geval-wie sal ek stuur en wie sal vir ons gaan. Die rûah en die s'eräfìm bevind hulle onder die aangesprokenes, wat deel uitmaak van die hemelse hofhouding.

Verwant hieraan is die toneel in Job 1:6 v., waar ons eweeens verplaas word in die troonsaal van Jahwe, waar die seuns van God, die benē ha'èlohîm hulle opstel voor Jahwe. Hierdie hemelse wesens, elders word hulle genoem be nē 'èlìm, maak dus ook deel uit van die hofstaat, in elk geval wesens waaraan ons 'n Elohimzugehörigkeit ${ }^{5}$ kan toeskrywe.

Nou het ons in die uitdrukking in Gen. 1:26, Laat ons . . maak so'n delibererende stelling te sien gerig tot die elohimsoortige wesens wat by sy troon staan. Waar hier in vs. 26 die werkwoord cāśa gebruik word,

3) Cf. Köhler-Baumgartner, Lexicon . . Libtos, 1953, bl. 786.

1) Th. C. VRIEzen, Hoofdlijen der Theologie van het O. Testament, 1954, bl. 191.

5) Fridolin Stier, Das Buch Ijjob, 1954, bl. 266. 
word in vs. 27 waar die in vs. 26 uitgesproke voorneme gerealiseer word deur God en deur God alleen, die werkwoord bār'ā in die enkelvoud gebruik om alle medeaandadigheid van die geraadpleegde elohimwesens uit te sluit.

In Gen. 3:22 afkomstig van die Jahwistiese skrywer word ook gebruik gemaak van die uitdrukking ons. Die teks lui: Toe het Jahwe Elohim gesê: Kyk, die mens het geword soos een van ons. 'n Vergelyking met die persoon van Jahwe is uitgesluit, juis deur d'e uitdrukking ,een van ons", waaronder die elohimsoortige figure verstaan moet word. ${ }^{6}$ Dieselfde verskynsel tref ons weer 'n keer aan in Gen. 11:7 in die geskiedenis van die toringbou van Babel, waar dit lui--Komaan, laat ons neerdaal en laat ons verwar... Dit is opmerklik dat in vs. 7 (eweas in Genl. :26) die meervoudige cohortatief, hier tweemaal gebruik word, om dan in die daaropvolgende vers (eweas in Gen. 1:27) tot die derde persoons enkelvoudsvorm oor te gaan.

Die nomen șèlèm(beeld) word deur Köhler ${ }^{7}$ afgelei van 'n in die Hebreeus onbevestigde stam șlm, wat in die Arabiese stam șalama, beteken ('n neus of 'n oor) af kap of afsny. Die plekke in die Ou Testament waar die begrip șèlèm voorkom hang met die stam saam met uitsondering van șèlèm in Ps. 39:7 en Ps. 73:20, waar dit hoogs waarskynlik terug te voer is tot die Akkadiese stam șalāmu met die betekenis van „swart of donker word." 8 Sèlèm met die betekenis standbeeld of beeldsuil word gebruik in 2 Kon. 11:18, 2 Kron. 23:17, waar dit genoem word naas die altare (van Baäl). In soortgelyke betekenis kom șèlèm voor in Eseg. 7:20, Amos 5:26. In Num. 33:52 word die gegote beelde so genoem. In die sin van 'n afbeeldsel, beeld of kopie verskyn die term in 1 Sam. 6:5, 11 en in Eseg. 16:17, terwyl in Eseg. 23:14 dit 'n aftekening of afbeelding of muurskildering is. „Sèlèm bedeutet allerdings überwiegend die reale Plastik." 9

Gen. $1: 26$ v., 5:1, 3, en Gen. 9:4 behoort inhoudelik byeen en daar staan șèlèm in die betekenis van beeld, image, Bild, d.w.s. 'n gestalte of gedaante. Nou word in Gen. 1:26 die voorneme uitgespreek om 'n mensheid, (hier kollektief gebruik), te maak, bessalmēnû, na ons beeld. Dieselfde werkwoord word gebruik in Gen. 9:6 waar gesê word na die beeld van God het hy die mens gemaak. In Gen. 1:27 waar die voorneme uitgevoer word maak die skrywer gebruik van die werkwoord bār'ā skep, ook in Gen. 5:1 waar gesê word „op die dag toe God die mens geskep het", om dan onmiddellik daarna weer te sê ,"na die gelykenis van God het hy hom gemaak". In Gen. 5:3 word verhaal dat Adam 'n seun verwek het na sy gelykenis, na sy beeld. Nou het Humbert na sy deeglike ondersoek na die begrippe beeld en gelykenis tot die slotsom geraak

6) Cf. G. von Rad, Das erste Buch Mose, ATD, 1953, p.78.

7) L. KöHLER, Lexicon, onder slm, asook Theologische Zeitschrift, p. 16v.

8) Cf. H. P. Wolmarans, Die Mens naar die beeld van God, 1932, p. 10v.

9) G. v. RAD, l.c., p. 44v. 
dat die mens na die uiterlik dieselfde voorkoms het as die godheid van wie hy 'n „effigie concrète et plastique" is, en dat die begrip hier net so min as in die ander gevalle waar dit verskyn, 'n geestelike ooreenkoms aandui. ${ }^{10}$ Ook Köhler geraak tot dieselfde slotsom waar hy sê dat "An all diesen Stellen ist „Gestalt" die richtige Uebersetzung und eigentlich gemeint". ${ }^{11}$

Die ander substantief demût, 'n verbaal abstractum afkomstig van die stam dmh-gelyk wees aan, wees soos, resemble, gleichen, kom 24 keer voor in die Ou Testament nl. in Gen. 1:26, 5:1, 5:3, 2 Kon. 16:10, Jes. 13:4, 40:18, Eseg. 1:5, tweekeer, $1: 10,1: 13$ ?, $1: 16,1: 22,1: 26$ driekeer, $1: 28,8: 10,10: 1,10: 10,10: 21,10: 22,23: 15$, Ps. 58:5, 2 Kron. 4:3. Die verspreiding van die woord oor die verskillende boeke van die Ou Testament is opvallend. Van die 24 keer waar dit gebruik word kom demût vyftien/sestien keer in Esegiël voor en driekeer by die priesterskrywer van Genesis. As ons ingedagte hou dat $\mathrm{P}$ en Esegiël hoogs waarskynlik tydgenote was, dan is die voorkoms van die woord des te merkwaardiger. ${ }^{12}$ $D{ }^{e}$ mût soos dit in Esegiël voorkom is in die vertaling moeilik weer te gee en dikwels moet die toevlug geneem word tot omskrywinge bv. gestalte, gelykenis, iets soos, wat daar uitsien as. In die troonwavisioen van Esegiël wat in Cap. 1:5 v. en 10 beskryf word en wat as doel het die tekening van die ligglans, $k^{\text {ebôd }}$ van Jahwe, kom die uitdrukking $\mathrm{d}^{\mathrm{e}}$ mût herhaaldelik voor, om wat die profeet waargeneem het aan te dui as gelykende op, wat daar uitsien soos. Heel tereg wys Stamm ${ }^{13}$ daarop dat demût by Esegiël „,wiederholt im abschwächenden Sinn gebraucht wird, um die Dinge der göttlichen Welt von Ihrer Entsprechung in der irdischen abzuheben". Ook Köhler ${ }^{14}$ en Jacob ${ }^{15}$ stem hiermee in dat demût, 'n verswakkende, temperende funksie vervul.

Die verskil in die voorsetsels waarvan die begrippe șèlèm en $\mathrm{d}^{\mathbf{e}} \mathbf{m u ̂ t}$ voorsien is, kom in die Afrikaanse Bybelvertaling nie uit nie, aangesien altwee weergegee word met die preposisie na. Meer aanneemlik sou dit wees om in die $b^{\text {e }}$ uitdrukking van eienskap ${ }^{16}$ te sien en wat dan heel goed weergegee kan word met as cf. Ex. 6:3, 18:4, Deut. 26:14, Jes. 40:10,

10) P. Humbert, Etudes sur le recit du paradis et de la chute dans la Genèse, 1940, p. 153v.

11) L. KöHLER, l.c., p. 19.

12) Op die affiniteit tussen $P$ en Esegiël wys W. Zimmerli, Biblischer Kommentar, Ezechiel XIIli, 1954. Cf. Gemser, 1.c., p. 194, Noot 14.

13) J. J. Stamm, Die Gottebenbildlichkeit des Menschen in Alten Testament (Theologische Studien), 54, 1959, p. 15v.

14) L. KöHLER, l.c., p. 21 sê: Es. nl. de mût dient überall zur Abschwächung einer Gleichheit ... Die Menschen sind in der (aufrechten) Gestalt Gottes geschaffen, aber doch nicht ganz so, sondern nur in dem Masse, dass es aussieht, als ob sie dieses Gestalt hătten. Damit ist die Würde und die Einzigartigkeit der Erscheinung Gottes gewahrt, wie es der ganzen Haltung der Priesterschrift gem âss ist.

15) E. JACOB, Theology of the Old Testament, 1958, p. 167-The term demut can have the same concrete sense as tselem ... but as its original force was that of resemblance its use by the author of Genesis in effect curbs and tempers the excessively material and plastic meaning that the first word might suggest.

16) Cf. C. Brockelmann, Hebräische Syntax, 1956, p. 98, asook Gesenius Hebrew Grammar, 2 English Edition by A. E. Cowley, 1910, p. 379. GeMser, l.c., stel voor die benaming bêt qualitatis, p. 192, Noot 8 . 
Eseg. $20: 41$, Ps. $31: 22,37: 20,54: 6$. Voor die hand lê dan die vertaling van Gen. 1:26a-Laat ons/ons wil mense maak, as beeld van ons.

Die ander substantief, die abstraktum $\mathrm{d}^{\mathrm{e}}$ mut is voorsien van die voorsetsel $\mathrm{k}^{\mathrm{e}}$, wat gewoonlik weergegee word met na, ooreenstemmend, ooreenkomstig, entsprechend, gemäss, according to. Nou kan $k^{\mathbf{e}}$ ook die maat ${ }^{17}$ aangee, Ex. 11:4, Num. 11:31, 16:21, 1 Sam. 20:3, waar Köhler, die betekenis weergee met, ongeveer. Heg ons hierdie betekenis aan die $\mathrm{k}^{\mathrm{e}}$, dan kom ons tot die volgende vertaling van Gen. 1:26:

Laat ons mense maak, as beeld van ons, ongeveer ons gelykenis.

Die grondbetekenis word bepaal deur die eerste begrip șèlèm, soos ook blyk uit vs. 27 , waar slegs dáárvan sprake is, waar demût nie weer herhaal word nie en ook in Gen. 9:6 waar bloot șèlèm gebesig word. Om die alte groot plastisiteit wat die begrip șèlèm meebring in te kort en te matig voeg die skrywer eksplikatief of glossatories ${ }^{18}$ die begrip d ${ }^{\mathbf{e}}$ mût daarby. Op drieërlei wyse gee die priesterskrywer uitdrukking aan die verskil wat daar is tussen die geskape mens en die skeppende God nl.:

1. Deur gebruik te maak van die pluralis in die passasie, word voorkom dat die ooreenkoms van die mens al te direk op God betrek word. God sluit in die ons die elohimwesens in. Die mens vertoon dus nie oerbeeld ${ }^{19}$ in sy enigheid in nie, maar wat die oerbeeld gemeenskaplik het met die elohimwesens.

2. Deur gebruik te maak van die voorsetsel $k^{\mathbf{e}}$ by die tweede substantief, op te neem in die sin van ongeveer, enigsins.

3. Deur gebruik te maak van die abstrakte nomen d ${ }^{\mathrm{e}}$ mût, wat eweas by die priester-profeet Esegiël, 'n sekere vaagheid en swewendheid aandui.

In aansluiting by die voorneme om mense te maak word gesê wat die doel en die taak van die te skeppe mense sal wees nl. om heerskappy uit te oefen oor die aarde, in die besonder oor die dierewêteld. Die uitdrukkinge, gebruik deur die priesterskrywer rādāh en kābaš dui strengheid en hardheid aan. E.g. werkwoord word ook gebruik vir die druiwe wat getrap word in die parskuip, Joël 4:13, dus trap, vertrap en dan heerskappy of gesag voer oor, domineer. Ook die vorm kābaš het 'n soortgelyke betekenis, trap of neertrap, onderwerp, oorweldig. Hierdie uitoefening van volstrekte gesag en heerskappy oor dierewêreld is die gevolg van die feit dat die mens as beeld van God geskape is. Die geskape wees as beeld van God stel die mens in staat om hierdie taak en doel uit

17) C. Brockelmann, l.c., p. 104, asook Köhler, Lexicon, p. 417, sub 3.

${ }^{18)}$ So W. Exchrodt, Theologie des A. Testaments, Dl 2, 1935, p 60 .

19) J. J. Stamm, l.c., p. 16., cf. G. v. Rad, l.c., p. 45, 46. Cf. ook P. Procksch, Theologie des A. Testaments, 1950 , p. 496 , waar hy sê: Der Plural muss gebraucht sein, um andere himmlische Wesen, also die Gottessöhne... in die Gleichung mit einzuschliessen. Nicht die Gottheit Gottes, seine Einzigkeit, Ungeschöpflichkeit und Heiligkeit ist der Vergleichspunt, sonders gewissermassen seine Natur, die auch in andern überirdischen Wesen zum Ausdruck kommen kann, in der Welt sich aber sonst nicht findet. 
te voer. Die skrywer het meer belangstelling vir die Aufgabe as vir die Gabe. ${ }^{20}$ Die mens kry nou volmag van God om hierdie funksie nl. die gesag oor die dierewêreld te voer, 'n taak wat tot dusver deur God self waargeneem is. By die gesag wat aan die mens verleen word word hy ook draer van die goddelike seën daarin dat hy in staat gestel word om hom voort te plant en te vermeerder, dat die aarde vervul sal word van beelddraers van God. Die mens kry as voedsel van God die plantaardige gewasse, dit het hy gemeenskaplik met die diere. Naas die vrymag en beskikking oor die dierewêreld, is hier 'n beperking, die lewe van die diere word gewaarborg, hier vind nog geen slag en eet plaas nie.

In Gen. 5:1-3 vind ons die eerste heenwysing na wat in Gen. 1:26 v. verhaal word. Beide werkwoorde daar gebruik, word ook hier aangewend, nou in die omgekeerde volgorde. Hier dra die mens reeds 'n eie naam Adam. Naas die in Gen. 1 verhaalde dat God die mens manlik en voulik geskape het, dat hy hulle geseën het, kom hier as nuwe element by die naamgewing van die mens. In 5:1 word gesê dat die mens geskape is bidmût 'elōhîm-as gelykenis van God. In 5:3 staan: Toe Adam 130 jaar oud was het hy ('n seun) verwek bidmûtô $\mathrm{k}^{\mathrm{e}}$ șalmô-as sy gelykenis, ongeveer sy beeld. Dit is dus nie net Adam wat die beeld van God gedra het nie, maar dit het in die daaropvolgende geslagte oorgegaan. „Für den Leser ist erst durch diese Ergänzung die Aktualität dieses Zeugnisses gesichert, denn der Hinweis auf einen zottesbildlichen Urmenschen wäre ohne diese Weiterung ein belangloses Mythologumenon." 21

Nog een keer word in Genesis 9:6 teruggekom op die begrip beeld van God. Daar staan:

Wie die bloed van die mens vergiet, deur die mens, sal sy bloed vergiet word, want as die beeld van God, het $\mathrm{Hy}$ die mens gemaak.

Die onaantasbaarheid van die menslike lewe word hier deur God op die voorgrond gestel; op moord volg die doodstraf. En aan die mens word opgedra om die lewe van die naaste te beveilig en by gewelddadige oortreding in te gryp en so die wil van God te voltrek. Die motivering van die bepaling geskied nie uit humanitêre oorwegings nie, maar dit word direk teruggevoer daarheen dat die mens gemaak is as beeld van God. Wie die mens aantas, tas die beeld van God aan en tas daarom God self ook aan.

Ten spyte van die oordeel met die vloed word die mensheid opnuut deur God geseën met die woorde:

En julle, wees vrugbaar en vermeerder, wemel op die aarde en beheers dit. ${ }^{22}$

20) G. von RAD, l.c., p. 46.

21) G. von Rad, l.c., p. 56

22) Baie waarskynlik is dit dat hier netsoos in Gen. 1:26v. die stam rdh moet lees en nie rbh, soos wat daar in die teks staan nie. temeer omdat rbh reeds verskyn in vs. $7 a$. 
Die heersersposisie van die mens in die tyd na die vloed, eweas in Gen. 1:26 word opnuut beklemtoon, en ondergaan tegelyk 'n aanmerklike uitbreiding daarin dat vrees en skrik vir die mens op die diere gelê word, 9:2. Naas die in Gen. 1 toegesegde plantaardige voedsel sal die diere ook voortaan dien as spys vir die mens.

Kom ons by Psalm 8 waar ook van die heersersposisie van die mens gewaag word, dan vind ons die volgende. Voorop stel die Psalmdigter die heerlikheid van Jahwe, pas daarna kom die hoogheid van die mens. Hy vang aan;

O, Jahwe, ons Heerser, hoe heerlik is u naam op die hele aarde, wat $\mathrm{u}$ majesteit gelê het op die hemele.

In vs. 5 v. kom die Psalmis dan tot die mens en sê:

Wat is die mens dat $u$ aan hom dink, en die mensekind dat $u$ op hom ag gee ${ }^{23}$

$U$ het hom 'n bietjie geringer gemaak as hemelse wesens, met heerlikheid en luister het $\mathrm{u}$ hom gekroon.

Die werkwoord hsr met die daaropvolgende min beteken ,iemand iets laat ontbeer in vergelyking met". Goed sou ons vs. 6 kon weergee met: $U$ het hom (die mens) iets laat kortkom by die elohim, wat heel goed ooreenstem met die inhoud van die verswakkende kidmûtēnû in Gen. $1: 26$. Die maatstaf van vergelyking is ook in hierdie geval die elohim of die goddelike wesens, maar om gelyk te wees aan die elohim kom daar iets $\mathbf{m}^{\mathrm{ec}} \mathrm{at}$, kort. Die mens het sy plek in die skepping onmiddellik onder die hemelse wesens en is in Out Testament terme uitgedruk elohimartig ${ }^{24}$ geskape. Heel duidelik kom ook hier uit dat die mens nie met Jahwe vs. 1 vergelyk word nie, maar met die goddelike wesens wat by die troon van Jahwe is. Die kroon van die mens wat hier besing word bestaan uit kābôd, heerlikheid of eer en hādār, luister of hoogheid. Nou word in Psalm 21:6 ook aan die koning hierdie kwaliteite toegeken ${ }^{25}$, waar staan

Groot is sy heerlikheid deur $\mathrm{u}$ hulp, majesteit en luister het $\mathrm{u}$ op hom gelê.

Maar ook God self beskik oor kābôd en hădār, Ps. 29:1, Ps. 96:6, Ps. $104: 1$, Ps. $145,5,12$. Hierdie trekke is anwesig by God, by die koning en by die mens. In die Psalm eweas in Gen. 1:26 v. en Gen. 9 word aan die mens as koninklike verteenwoordiger van God op die aarde die heerskappy oor die werke van sy hande opgedra. Hier heet dit;

23) Die werkwoord pkd waar Jahwe/God subjek is word in die Afrikaanse Bybel heel dikwels weergegee met ag gee op, so bv. in Gen. 50:24, Ex. 4:31, 30:19, 1 Sam. 2:21 (cf. hier Gen. 21:1), Jer. 27:22, 29:10. Die verbinding $z \mathrm{kr}$ en pkd vind ons ook in Jer. 15:15.

24) G. von RAD, Theologie des Alten Testaments, Bd. Ip. 149.

25) Bentzen, in sy Messias Moses redivieus Menschensohn, p. 12, maak hier die afleiding dat in Psalm 8 sprake is van die oerkoning en die oermens soos wat dit voorkom in die sakrale koningsideologie. Op die verwantskap tussen Gen. 1 en Psalm 8 wys BENTZEN eweeens cf. ook p. $38 \mathrm{v}$. 
$\mathrm{U}$ laat hom heers oor die werke van $\mathrm{u}$ hande, alles het $\mathrm{u}$ geplaas onder sy voete, skape en beeste, hulle almal, en ook die diere van die veld, voëls van die hemel en visse van die see, wat trek deur die paaie van die see. ${ }^{26}$

Baie duidelik kom ook hier die heersersbevoegdheid en die heerserswaardigheid van die deur God bekroonde mens uit. . . .,,was in Gen. 1 und Ps. 8 über die Hoheit des Menschen ausgesagt wird, (ist) Hinweis auf ein absolut gültige, unaufhebbare Setzung Gottes ... Der Mensch gehört zur Welt Gottes. Von Gott hat er unfassbare Herrschaftsbefügnisse verliehen bekommen und ist mit Ehre und Majestät gekrönt worden." 27

As laaste perikoop in hierdie verband kan ons noem Esegiel 28:11-19. In sterk mitologiese kleure word die koning van Tirus met die paradysmens vergelyk, wat omrede van sy sondigheid vs. 16 uit Eden, die tuin van God, vs. 13, uit sy bevoorregte heersersposisie verdryf is. Alhoewel die passasie meer ooreenkoms vertoon met die verhaal van die Jahwis in Gen. 3, werp dit ook lig op die verhaal van P. Die aanvangswoorde is duister. Jy was hôtēm toknît, in die AV weergegee met ,die seëlring van eweredigheid", deur NBG weergegee met ,volmaakt van gestalte" en in die Revised Standard Version 1957, signet of perfection. Die uitdrukking hôtēm toknît kan ons weergee met - beseëlaar van die voor-beeld. ${ }^{28}$ Van die mens wat in Eden, in die tuin van God gewoon het, word hier gesê dat hy op die dag toe hy geskape is ${ }^{29}$, vs. 13 en daarna, vs. 15 totdat daar verkeerdheid in hom gevind is, vol wysheid, vse. 12 en 17, volmaak in skoonheid, vse. 12 en 17 , volkome in sy weë, vs. 15 en heilig was, vse. 16, 18. Die ,heerlikheid en die luister" van die geskape mens (Psalm 8) as beeld van God (Gen.), word hier met ander beelde beskryf, dog 'n verwantskap tussen die in die verskillende perikope uitgedrukte gedagtes val nie te ontken nie.

Die mens is geskape as beeld van God. Anders as die diere staan die mens in sy verhouding tot God. By sy skepping kom daar van Gods kant af 'n besondere voorneme of wilsbesluit tot uiting. Die doel en die taak wat aan die te skeppe mens opgedra word is die heerskappy oor die deur God geskape dierewêreld. Dit hou egter nie in dat die beeld van

36) Die "wat trek deur die paaie van die see" is nie bystelling by die visse van die see nie, maar slaan op 'n aparte kategorie en wel die groot seediere die tanninim in Gen. 1.21, wat ook daar onderskei word van die ander seediere. In Gen. 1:26 en 28 strek die heerskappy van die mens hom naas dié oor die ander diere ook uit oor die visse van die see, dit is ook die geval in Gen. 9:2. Hier in Psalm 8 word die heerskappy van die mens verder uitgebrei dat hy ook heers oor die uiters moeilike-bedwingbare kreature nl. die tanninim. Cf. Jes. 27:1, 51:9, Ps. 74:13, Job 7:12.

17) H. J. Kraus, Psalmen XVi, Biblischer Kommentar, 1958, p. 72.

28) Dieselfde woord toknit kom ook voor in Eseg. 43:10, waar dit vertaal word met voorbeeld of model.

20) Die feit dat hier gebruik gemaak word van die werkwoord br', wat ook deur P gebruik word, kan wys op die enersheid van die gedagteklimaat van Esegiël en die priesterskrywer. Die ander aangewende stof kom uit die J. verhaal, b.d. Eden, tuin van God, gerub, godeberg. 
God in die heersersbevoegdheid van die mens oor die diere bestaan nie ${ }^{30}$ lg. is die gevolg van die as-die-beeld-van-God geskapenheid vadie mens ${ }^{31}$. Om die karakter van die beeld van God te bepaal is nodig dat ook hierdie uitdrukking gesien word teen die agtergrond van die gemeenskaplik oosterse voorstellingswêreld, waar die mens in direkte verband, ook liggaamlik, met die godheid gebring word. Die priesterskrywer in sy worsteling om die verhouding van die mens tot God uit te druk, wend die hom bekende terminologie aan, want ook sy ,voorstelling kan den kring van eigen ondervinding niet te boven gaan". ${ }^{32}$ Die begrip șèlèm is eerstens in sy eintlike betekenis op te neem, nl. gestalte, maar onmiddellik daarby die verswakkende eksplikatiewe demût. Die verklaringe wat die beeld van God beperk tot 'n ,,suiwer geestelike", met verontagsaming van die uiterlike, is strydig met die inhoud van die begrip sèlèm. Ook die liggaamlike verskyningsvorm van die mens is ' $\mathrm{n}$ wonder van God. ${ }^{33} \mathrm{cf}$. Ps. 139-13-16. Ou Testamenties gesien is die mens 'n eenheid. „Soul and body are so intimately united that a distinction cannot be made between them. They are more than united, the body is the soul in its outward form." "34 Dit blyk ook uit Gen. 2:7--So het dan die mens 'n lewende siel geword. Die mens is 'n ,,animated body" en nie 'n ,,incarnated soul" nie. $\mathrm{H}$. Wheeler Robinson. In sy totaliteit is die mens as beeld van God geskape. As in Gen. 5:3 verhaal word dat Adam 'n seun verwek as sy gelykenis, ongeveer sy beeld, dan is die afleiding voor die hand liggend, dat die seun die beeld van die vader vertoon, sowel na die uiterlike as wat die meer geestelike eienskappe betref, sonder om die een ten koste van die ander te benadruk.

Nou bly die vraag oor of die meer ,geestelike" sy van die begrip beeld van God nader bepaal kan word. In die loop van die tyd is dit in verskillende rigtings gesoek en verklaar, so deur Procksch in die persoonlikheid van die mens, met sy bewussyn en wil en die daarmee gepaard gaande sedelike verantwoordelikheid ${ }^{35}$; deur Eichrodt in die vermoë van bewussyn en selfbepaling of anders uitgedruk ,eine Verbindung mit Gott, durch die der Mensch auch als Sünder ein zur geitigen Gemeinschaft mit Gott fähiges Vernunftwesen bleibt". As bewuste Ek word hy deur Gods woord bereik en kan so tot verantwoordelikheid geroep word. ${ }^{36}$ Die begrip beeld van God druk 'n gemeenskapsverhouding uit, sonder om die in-die-gemeenskap tredende lede gelykwaardig te stel. „The imago Dei

30) So L. KöHLER, in die eerste drukke van sy Theologie des A. Testaments. In die 3de uitgawe, 1953, so wel as in Th.Z., l.c., sien hy die beeld van God in die ,,aufrechte Gestalt des Menschen" cf. e.g. p. 134, 242.

31) C.f. Th. C. VRIEzEN, Hoofdlijnen, p. 220, asook Eichrodt, Theol., p. 63.

$\left.{ }^{32}\right)$ F. M. Тн. BöнL, Genesis I., TU., 1923, p. 62.

33) Cf. B. Gemser, Psalmen III, TU, 1949, p. 71, 205v. Alhoewel die stam br' nie in vs. 13 gebruik word nie vertaal Gemser, heeltemal tereg, met skep. Die verwondering kom veral uit in vs. 14 , wat deur GEMSER treffend mooi weergegee word met-lk belijd $U$, omdat ik op mysterieuze wijze wonderlijk gemaakt ben; wonderlijk zijn Uw werken!

34) Joh. Pedersen, Istael, its Life and Culture, 1-11, p. 170 .

35) O. Proкsch, Theologie ..., p. 496.

36) W. EIchrodt. Theologie..., p. 62, 63, cf. K. BARTH, Kirchliche Dogmatik, III/1, 1945 , p. 205 v. 
means for man a relationship with and dependance upon, the one for whom he is only the representative. To remain an image man must retain his relationship with God, he must remember that he is only an ambassador and his dominion over creation will be effective only in proportion as that relationship becomes more real." ${ }^{37}$ Vriezen $^{38}$ sien in die begrip beeld van God uitgedruk dieselfde innige verhouding as die van vader en kind, 'n term wat die priesterskrywer bewus wou vermy omdat dit assosiasies kon opwek wat aanstoot sou kon gee. Met die verdieping wat die begrip beeld van God in die Nuwe Testament ondergaan, skyn die uitdrukking kind van God die mees adekwate interpretasie van die Ou Testamentiese beeld van God te wees.

E. S. Mulder

Universiteit van Pretoria,

September 1959. 